\title{
Transferring agricultural machines from field to the laboratory for emission check
}

\author{
Prof. Danilo Engelmann Berner Fachhochschule, Biel, $\mathrm{CH}$; \\ Simon Becker M. Sc., Karlsruhe Institute of Technology, Karlsruhe, DE; \\ Prof. Roger Stirnimann, Berner Fachhochschule, Zollikofen, $\mathrm{CH}$;
}

\begin{abstract}
Mobile machines are very versatile and different in their design and in the tasks they can handle. Tractors for example can be combined with different implements to work in agricultural processes. This variety must be considered during development, testing and inspection of exhaust gas aftertreatment systems. In this paper, one approach conducts In-Use measurements during field operation of a tractor with implement. While this takes environmental influences into account, In-Use measurements are barely reproducible, although tests on a chassis dynamometer are highly reproducible. Known road load simulation techniques for cars are not transferrable for mobile machines on chassis dynamometers due to different drivetrain topologies and changing parameters during field operation. To transfer field measurements to the roller test bench in the laboratory, a method is proposed to control the vehicle speed and motor torque to the same values recorded in the field.
\end{abstract}

\section{Motivation}

Mobile machinery are very complex machines with numerous components. In addition, they are also operating in a great variety of tasks. As an example, the agricultural tractor is used widely in different applications from transportation to soil tillage. Therefore, it is equipped with a special powertrain to fit in all the different intended agricultural tasks.

Besides the fact that they have to perform their tasks, it is also necessary to fill in completely a catalogue of requirements indirectly related to the working tasks of the machine. One of these requirements is e.g. the emission standards. Emission standards for agricultural tractor were introduced for more than twenty years ago and emission limits have been constantly lowered [1]. Today's focus of further development and testing exhaust gas aftertreatment systems (EAT) is the In-Use measurement in order to adapt the exhaust gas aftertreatment to the prevailing boundary conditions of the task in question for the machine. This allows to adapt the EAT and even increase its performance. Unfortunately, the downside is that In-Use measurements come with certain limitations for the development process, such as limited reproducibility and high expenses to prepare and conduct field measurements. Therefore, in 
context of EAT development, a procedure should be proposed to allow the advantages of the In-Use measurements to integrate the development process while minimizing the associated limitations of this kind of measurements.

\section{Testing emission in mobile machinery}

For evaluating the emission behavior of a machine during the development of the mobile machine, the intended engine and exhaust gas aftertreatment system are tested often on an engine test. The engine test bench allows a precise validation of the emissions because a specialized measurement equipment is used. Environmental conditions are often kept constant from the test bench's auxiliary. This ensures a detailed and high reproducible investigation of the engine, exhaust aftertreatment system components with their parameters and functions. However, influences from the later powertrain, machine systems or environment are difficult to impress on the units under test. These influences on the emissions could be considered when a model based approach like in [2] is used. A simulation model provides the inexistent influences of the other systems; therefore, the method has to be adapted in a mobile machinery work frame like in [3]. In the case of legislative issues, like homologation or check-ups, specific cycles are often synthetized from different work tasks. This does not necessarily fit to the intended task in which the machine will be used later to ensure an equal base of reference for all. Until now model based approaches are not considered in emission legislation. In summary, it can be said that the tests on the test bench provide detailed and precise reproducible results.

On a chassis dynamometer the whole machine is tested, this ensures by itself the influence of the machine sub systems on the powertrain and as well as on the emissions. While the drivetrain is loaded by the roller dynamometer, appropriate roller dynamometers are needed to meet the power requirements of mobile machines [4]. The load of possible implements is often simulated by an adapted load unit for the power take-outs. So, this type of testing application is already near to the intended use cases to represent fieldwork. The advantage of the roller dynamometer based test method is the reproducibility of the load profiles. Precise measurement equipment for exhaust gas can be used and even the tires surface contact can be considered as constant.

The quality of load cycles determines a major impact on chassis dynamometer test results. If those are too simplified, the test does not represent the intended field task precisely enough. This is not the case when the machine is tested in its intended work process, a so called in use measurement. With this test, the influencing factors on emission are naturally correct for 
the test set-up. To measure the emission of the mobile machine, it is common to use a portable emission measurement system (PEMS) $[5,6,7]$. Since the space on the machines is usually extremely limited and the equipment can be very voluminous, the use of PEMS in the machine application is complex. It can be difficult to avoid influences on the machine process from the measurement.

\section{Combining reproducibility and realistic loads}

Both field tests and chassis dynamometers have their specific strengths. While one gives the best results but is poorly reproducible, the other one needs a big effort to simulate the missing environmental influences. However, it allows a good level of reproducibility. The question arises if it is possible to combine the recorded loads and other data from the field test with the dynamometer to be as close as possible to reality of the measurements and being reproducible in the same time because of the use of the dynamometer.

This paper tries to show a possible way to perform realistic test-drives on a chassis dynamometer based on recorded field tests. Based on measured data of an agricultural tractor during field test a suitable road simulation, respectively field simulation has been worked out. The following chapter will demonstrate the procedure.

\section{Road simulation on the dynamometer}

A frequently chosen mode of operation on the dynamometer is road simulation. When a vehicle drives on the road, it is subject to several resistance forces. These are rolling resistance, air resistance (drag), climbing resistance and acceleration resistance [8].

$$
F=m g f_{r}+\frac{1}{2} \rho_{L} c_{w} A v^{2}+m g \sin (\alpha)+m \ddot{x}
$$

In order to simulate these driving resistances on the test bench, the coefficients of a polynomial are determined by performing coasting experiments. This helps in finding a correlation between driving resistances and velocity [9].

$$
F=C_{1}+C_{2} v+C_{3} v^{2}
$$

To do this, the vehicle is accelerated to a speed on a flat surface and then disconnected from the drivetrain by disengaging the engine. The time needed for the vehicle to reach a lower speed or to come to a complete stop, is then measured.

For this procedure, the driver must disengage the drive motor from drivetrain while driving. This is often not possible for mobile machines. Other assumptions of road simulation are not valid for field trips of tractors. These are:

- The drive motor cannot be separated from the powertrain (hydrostatic / power split / cvt transmission). 
- The operating weight changes during operation (loader wagon, manure tanker).

- The rolling resistance changes during operation (field / road, different types of soil).

- The tire pressure can change via a tire pressure regulator.

\section{Adaptation of road simulation for field operations}

The aim of the approach is to reproduce a test drive from the field as precisely and reproducibly as possible on the chassis dynamometer. For this purpose, relevant data of the vehicle are recorded during field deployment. These include engine speed, engine torque, tractive force and driving speed and map the exact operating state of the vehicle at any time. The combustion engine is well defined through the engine speed and torque. In combination with the driving speed, the gear ratio is defined as well. This information are needed to create the same conditions for the vehicle on the dynamometer via two control loops.

On the one hand, the speed profile is traced out of the field via a driving robot. On the other hand, the dynamometer is operated in force-controlled mode. The set point force is specified to the test bench in such a way that the same moment present during the field test is applied to the wheels or the motor, in harmony with the speed. Figure 1 shows the structure of the control loop.

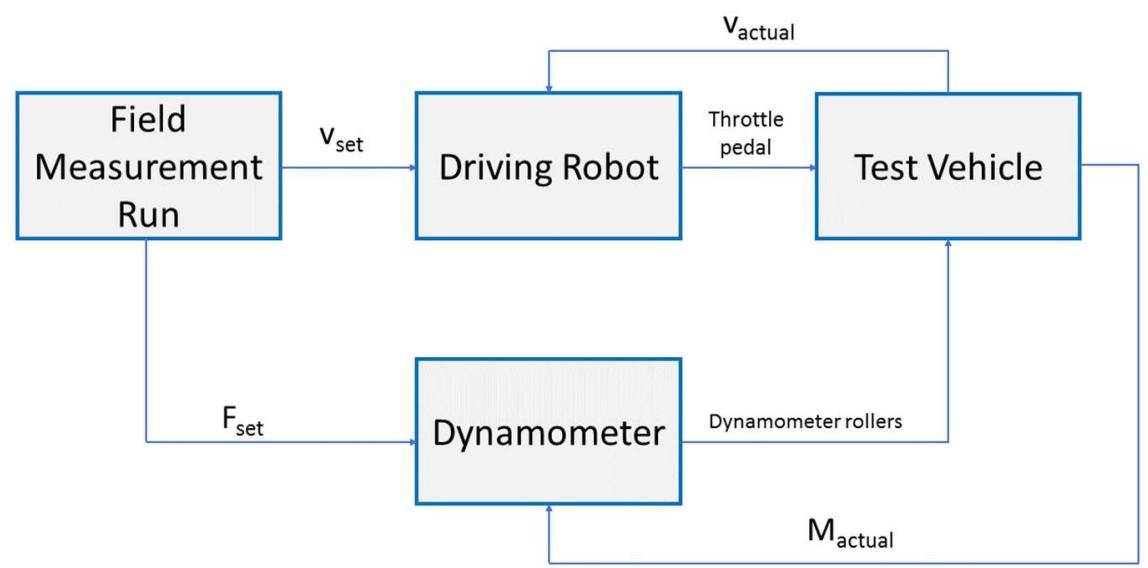

Figure 1: Closed-Control loop for road simulation in field operation

\section{Results}

The method was tested with a medium sized tractor which performed field work. The tractor was equipped with a PEMS to record emission values and log position, speed, loads and other important data of the machine. As an example, the recorded data during stubble cultivation is shown in Figure 2. 


\section{Stubble Cultivation with Disc Harrow, with Slope}
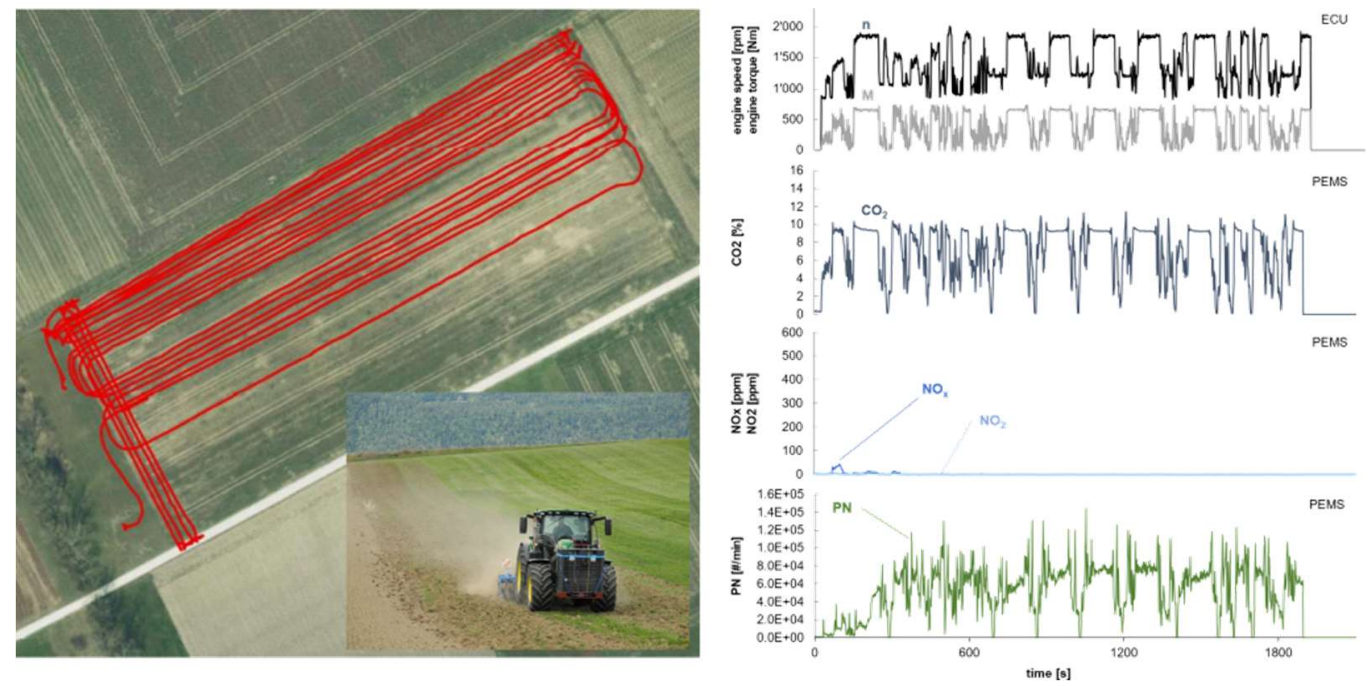

Figure 2: Recorded data

On the chassis dynamometer the recorded data are used as reference variable for the developed road simulation procedure. The same PEMS used during the field test was also used on the chassis dynamometer to avoid deviations due to change of the machine set-up or different measuring methods from other measurement equipment. In the case of stubble cultivation, the attachment is already considered in the recorded tractive force respectively in the engine torque. This test set-up allows any deviations of the results to be attributed to the method and its implementation.

One important influence on the emissions is the load of the engine. In Figure 3, the tractive force of the tractor is represented by the blue graph. The red graph represents the tensile force adjusted on the chassis dynamometer. It can clearly be seen that the force curve is almost the same. Individual jumps which occurred at the end of the recording exceed the existing dynamics of the test bench and therefore cannot be mapped.

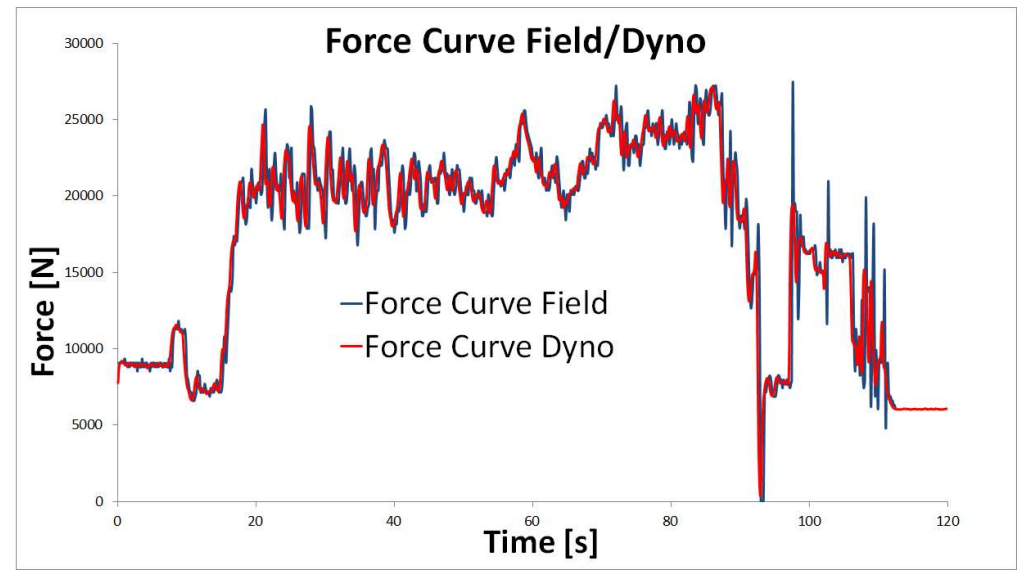

Figure 3: Tractive force curves in the field and on the roller test bench 


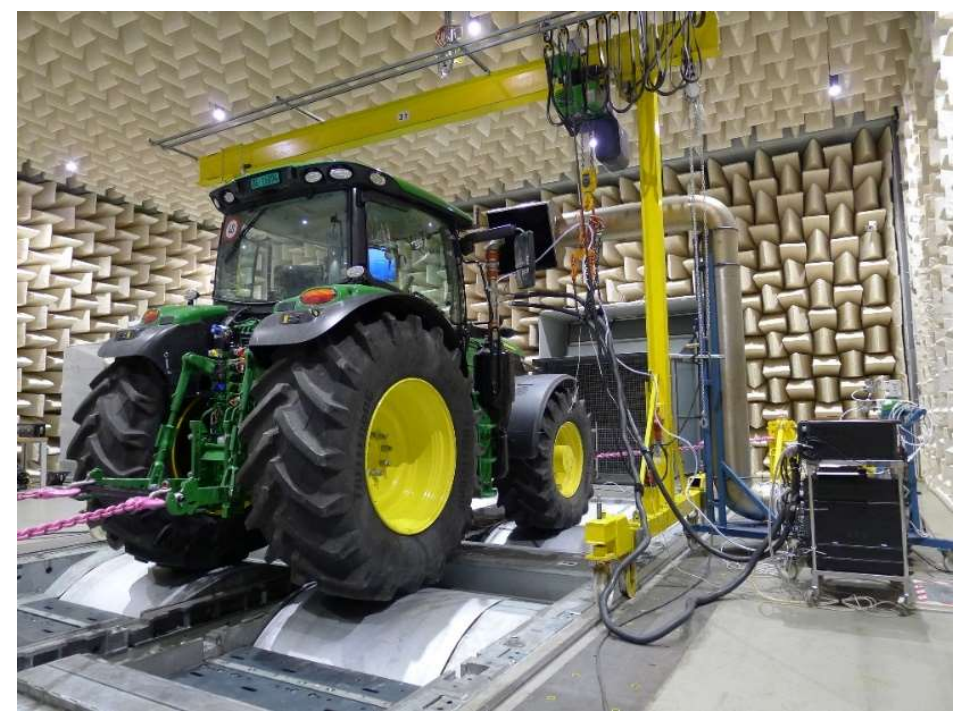

Figure 4: The tractor for field tests is used to reproduce the former fieldwork on the chassis dynamometer

The precise reproduction of speed and load is also reflected in the measured data. As shown in Figure 5, the performed work and the $\mathrm{CO}_{2}$ emission are for the chassis dynamometer and the field test similar. Minor downward deviations can be explained by slightly different temperatures, air pressure and control deviations of the test bench.
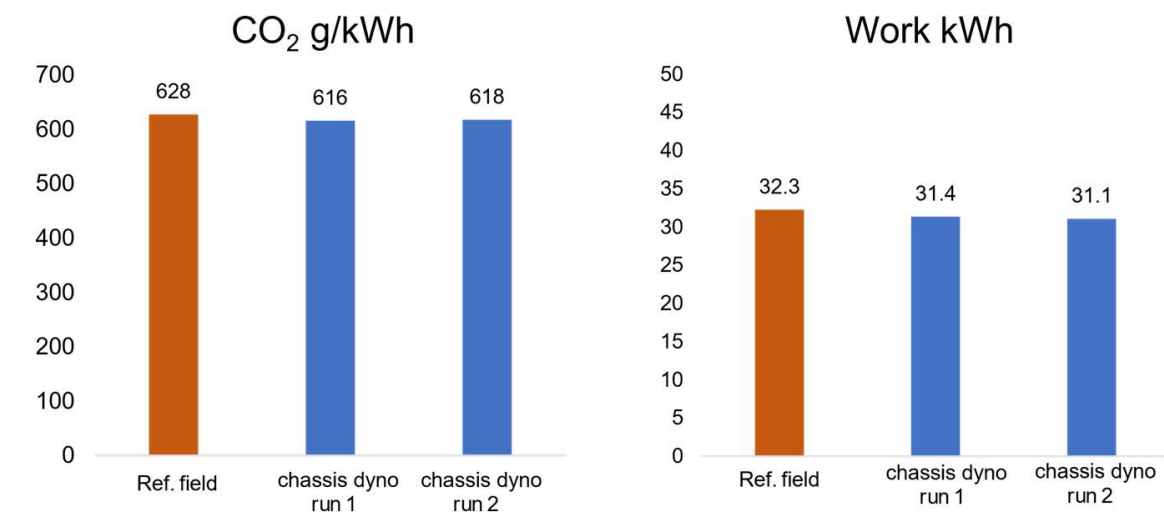

Figure 5: Performed work and $\mathrm{CO}_{2}$ emissions

A look at the legally limited emissions shows a similar picture. The result is the same for all considered emissions. They are all on the same scale and quite low. No major deviation upor downwards to the measured values on the field have been observed. 


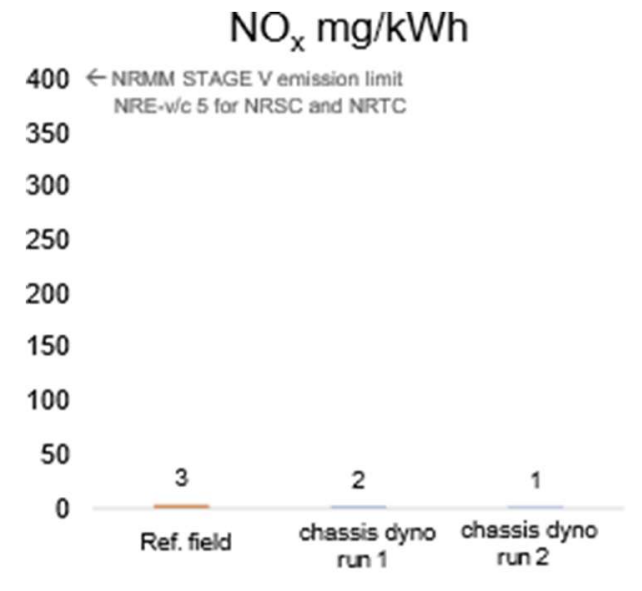

$\mathrm{THC} \mathrm{mg} / \mathrm{kWh}$

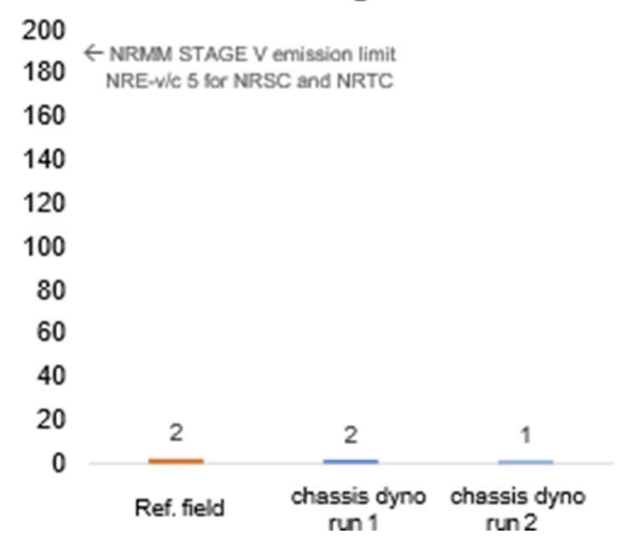

\section{$\mathrm{CO} \mathrm{mg} / \mathrm{kWh}$}

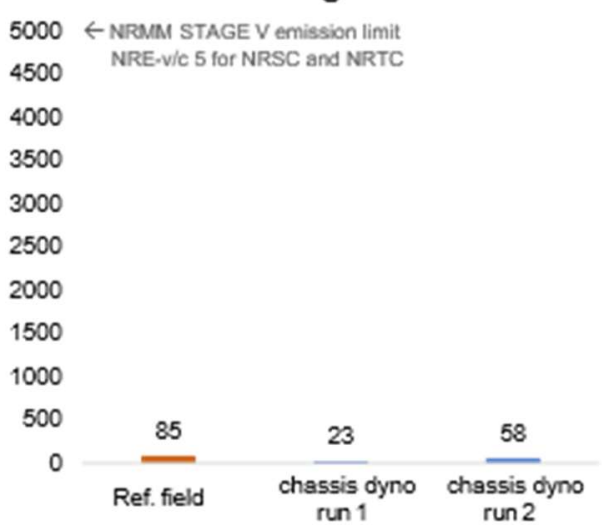

$\mathrm{PN} \# / \mathrm{kWh}$

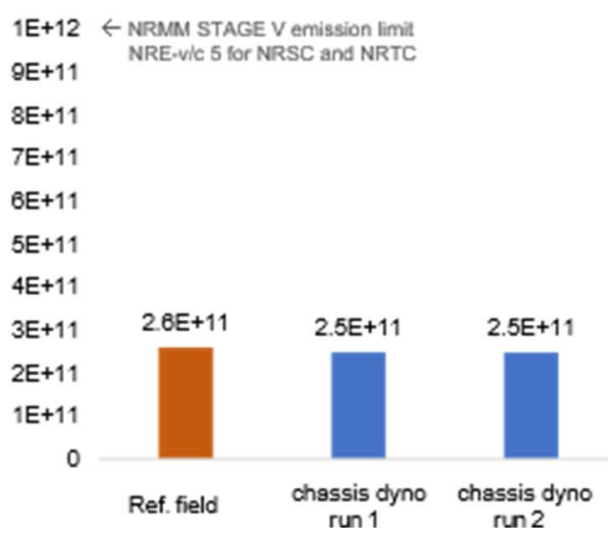

Figure 6: Comparison of emissions in the field and on the test bench

\section{Summary}

The two methods of the field test and the chassis dynamometer test are a promising approach. The procedure presented here shows a way to combine the advantages of both.

Measured application cases can now be reproduced without making too many simplifications and thus distorting the results. This is an important tool for check-up in development and other kinds of emission issues. This may further improve the emission behavior of heavy machinery.

\section{Literature references}

[1] Stirnimann, R.; Engelmann, D.: Entwicklung bei Traktormotoren in den letzten 20 Jahren. ATZoffhighway 10 (2017) 4, S. 70-77

[2] Disch, C., Koch, T., Spicher, U. u. Donn, C.: Engine-in-the-Loop als Entwicklungswerkzeug für die Emissionsoptimierung im Hybridkontext. MTZ Motortechnische Zeitschrift 75 (2014) 10, S. 70-78 
[3] Brinkschulte, L., Engelmann, D., Siebert, J., Iwanicki, M. u. Geimer, M.: MOBiL - Eine auf mobile Arbeitsmaschinen optimierte Prüfmethode. In: Wissenschaftlicher Verein für Mobile Arbeitsmaschinen (Hrsg.): Hybride und energieeffiziente Antriebe für mobile Arbeitsmaschinen. 6. Fachtagung, 15. Februar 2017, Karlsruhe. KIT Scientific Publishing 2017, S. 173-194

[4] Dreher, T., Frey, M., Gauterin, F. u. Geimer, M.: Akustik-Allradrollenprüfstand für mobile

Maschinen. ATZoffhighway (2011) 09, S. 66-73

[5] Gietzelt, C., O. Dregrell und K. Mathies: Mobile "in-use" Emissionsmessung mit PMSMesstechnik an mobilen Maschinen (non road). Tagung Land.technik 2012, Karlsruhe 6. und 7.11.2012. In: VDI-Ber. 2173, S. 95-101. Düsseldorf: VDI-Verlag 2012.

[6] In-Service Monitoring of Non-Road Mobile Machinery (ISM NRMM) - Pilot Project on Agricultural Tractor, Federal Office for the Environment (FOEN) Report 521a, Engelmann, D., Czerwinski, J. u. Stirnimann, R., Bern 2018

[7] Abgasverhalten von Fahrzeugen im realen Betrieb mit alternativen Kraftstoffen. Berichte aus dem TFZ Nr. 62, Huber, G., Thuneke, K., Emberger, P. u. Remmele, E., Straubing 2019

[8] Hoepke, E. u. Breuer, S. (Hrsg.): Nutzfahrzeugtechnik. Grundlagen, Systeme, Komponenten. ATZ / MTZ-Fachbuch. Wiesbaden: Springer Vieweg 2016

[9] Mayer, W., Wiedemann, J. u. Neubeck, J.: Fahrwiderstands-bestimmung im realen Fahrbetrieb.

ATZ - Automobiltechnische Zeitschrift 104 (2002) 5, S. 484-491 